\title{
DESEJO, SENTIMENTO E RELAÇÃO COM O OUTRO NA FILOSOFIA DA VIDA DE RENAUD BARBARAS*
}

\author{
Reinaldo Furlan** \\ https://orcid.org/0000-0003-2117-3886 \\ reinaldof@ffclrp.usp.br
}

RESUMO Nossa intenção é apresentar a filosofia da vida de Renaud Barbaras, reunida em Le désir et le monde, e o lugar que ela nos parece ocupar na fenomenologia. Barbaras divide sua filosofia da vida em três níveis: fenomenológico, cosmológico e metafísico. Sem deixar de contemplar seu projeto total, nosso enfoque será mais fenomenológico, destacando, e discutindo, suas noções de desejo, sentimento e relação com o outro.

Palavras-chave Renaud Barbaras. Fenomenologia. Desejo. Sentimento. Amor.

ABSTRACT Our intent is to present Renaud Barbaras'philosophy of life, assembled in his book 'Le désir et le monde', as well as the place it seems to us it occupies in phenomenology. Barbaras divides his philosophy of life in three levels: the phenomenological, the cosmologic and the metaphysic levels. Though not foregoing his overall project, our focus will be rather a phenomenological one, highlighting and discussing his notions of desire, feeling and relationship with the other.

Keywords Renaud Barbaras. Phenomenology. Desire. Feeling. Love. 


\section{Introdução}

No que talvez possamos chamar de uma primeira etapa de sua filosofia, Renaud Barbaras, na sequência dos fenomenólogos pós-husserlianos, em particular de Merleau-Ponty, procura fundar o sentido da correlação fenomenológica, consciência e mundo, como desejo da vida. Como diz Barbaras (2016a,p. 84), o desejo é o sentido mais profundo da intencionalidade fenomenológica, desejo que é movimento em direção ao mundo, como mostra Sartre, mas que é vital, em um sentido bastante radical, porque contemporâneo da constituição do próprio ser vivo (2008, p. 201; 2013, p. 153). Assim, Barbaras também se apoia na e se separa da filosofia da vida de Hans Jonas, que concebe a vida essencialmente como movimento em direção ao mundo, mas fundado na noção de metabolismo, isto é, na necessidade de troca incessante de matéria do organismo com o meio. Ora, mostra Barbaras em mais de um lugar, com o metabolismo Jonas perde não só no caráter transcendental do movimento da vida, mas também no estatuto do próprio movimento vital, pois a ideia de satisfação da necessidade, implicada no conceito de metabolismo, privilegia, contrária à intenção do próprio autor, a concepção de um indivíduo formado, acabado, que se movimenta para manter seu equilíbrio metabólico, quando, a rigor, há somente individuação da vida, contrariando, como veremos mais à frente, nossa arraigada crença de uma visão substancialista da vida (Barbaras, 2008, pp. 213, 215).

Também poderíamos dizer que Barbaras procura fundar a correlação fenomenológica no desejo da vida, que se expressa na ambiguidade do termo "viver" (no francês e no português), que significa estar em vida, no sentido intransitivo do termo, e viver sentidos de..., no sentido transitivo do termo, distintos, no alemão, como leben (viver) e erleben (vivenciar). O desejo é o termo que os reúne, explicitando fenomenologicamente seus sentidos como ser desejante do mundo (Barbaras, 1999, pp. 110, 160-161; 2013, p. 134).

Em síntese, podemos dizer que a fenomenologia da vida de Renaud Barbaras é a tentativa de explicitação concreta da correlação fenomenológica, se considerarmos que, para ele, as tentativas que o antecederam fracassaram de alguma forma nessa tarefa, seja não superando completamente a abstração do polo subjetivo da correlação fenomenológica, expresso classicamente com o termo "consciência", seja em prejuízo do polo transcendental da correlação, expresso com o termo "mundo".

No primeiro caso, da abstração do polo subjetivo, além do próprio Husserl, segundo Barbaras (2016b, p. 240), destacam-se Heidegger, Sartre e Merleau-Ponty, os quais, mantendo a prioridade da abertura de mundo na percepção, de alguma forma falham na apreensão da concretude do sujeito 
da percepção. Grosso modo, pois não será esse nosso objeto de discussão, Heidegger falha porque entende de maneira muito limitada o conceito de pulsão, que ele vincula à necessidade animal e, assim, a objetos determinados; por isso a pulsão não abre, propriamente, mundo, mas se encerra no circuito da necessidade animal. ${ }^{1}$ Barbaras (2011a, p. 55) destaca que Heidegger vincula a abertura de mundo do Dasein a um estado de afecção, que é a maneira com a qual Heidegger "aterra" (o termo é nosso) o Dasein no mundo, seu ser-nomundo; a questão, para Barbaras, é se a afecção é suficiente para mostrar o movimento do Dasein em sua compreensão de mundo. Sartre falha porque, por definição, o polo subjetivo é negatividade pura, mas não vital, como dissemos (Barbaras, 2016a, p. 121). E Merleau-Ponty, porque, a despeito de sua tentativa de unir a abertura da percepção ao corpo, não é capaz de realizála a contento, na falta de um sentido mais profundo do movimento corporal (Barbaras, 2016b, p. 208). Podemos dizer que falta a Heidegger a noção de desejo, tal qual Barbaras a enseja; a Merleau-Ponty falta radicalizá-la, pois o desejo permanece em sua filosofia no nível dos termos estabelecidos da correlação, antes de gerá-los; ${ }^{2}$ e a Sartre falta a apreensão do desejo como negatividade natural.

No segundo caso, de subtração da abertura do mundo, temos o próprio Hans Jonas (Barbaras, 2008, pp. 207, 209; 2011b, p. 164), que com o conceito de necessidade fica aquém da abertura da consciência na percepção do mundo - condição para o conhecimento, propriamente dito -, mas o principal destaque é Michel Henry, cuja fenomenologia da vida apreende o lado concreto do polo subjetivo da correlação, porém à custa da relação originária com o mundo (Barbaras, 2008, p. 9; 2016b, p. 246). Como Barbaras pergunta em mais de um lugar, com o próprio Henry, se a intencionalidade da consciência é o sentido da correlação fenomenológica ou o ponto de partida da fenomenologia, como ela está presente à própria consciência? Não pode ser de maneira intencional, o que levaria a questão a uma regressão infinita. Nesse sentido, Henry afirma a experiência de imanência da consciência como um dado originário da vida, mais precisamente, o pathos originário da vida como autoafecção, ${ }^{3}$ com o qual ele defende um dualismo ontológico contra o monismo da tradição

1 A tese da pobreza do mundo animal em Heidegger baseia-se na sua diferença entre pulsão e percepção (Barbaras, 2003, p. 188). Para uma síntese da crítica de Barbaras à noção de pulsão em Heidegger, ver Ramos (2012, pp. 168-169).

2 Barbaras (2003, p. 156) acusa em Merleau-Ponty a incapacidade de superação do duplo empírico-transcendental da fenomenologia; primeiro entre consciência e objeto, com a noção de corpo próprio, e depois entre a minha carne e a carne do mundo. Conferir, também, Barbaras (1999, pp. 108-109; 2011a, pp. 90-92).

3 Trata-se, pois, de inverter toda a fenomenologia que parte da abertura e manifestação do mundo (Henry, 2000). 
fenomenológica que toma a abertura da consciência ao mundo como solo fundamental da fenomenologia. Mas Barbaras jamais abriu mão da perspectiva da heteroafecção. Como ele sintetiza a questão com Merleau-Ponty, é preciso apreender a unidade entre a presença a si, sem a qual a consciência "espatifarse-ia nas coisas" (Barbaras, 2011b, p. 181), e a percepção do mundo, a uma só vez como diferentes e inseparáveis, a diferença no mesmo.

Em síntese, duas perspectivas fenomenológicas, portanto, em sentidos opostos: transcendência e imanência, ${ }^{4}$ heteroafecção e autoafecção, nos termos que Barbaras gosta de usar para diferenciar a fenomenologia de Henry daquela do primeiro grupo, do qual ele é mais próximo na maior parte do seu percurso filosófico, para, finalmente, chegar a um equilíbrio que consideramos o grande trunfo de sua filosofia nesse jogo de cartas da fenomenologia. Como veremos, Barbaras terminará unindo essas duas tradições, ao chegar a uma concepção de passividade superior que não é intencionalidade de nada (como diz Henry) porque é pura receptividade de mundo, que implica a atividade de abertura ou transcendência pura, sem conteúdo algum, nível originário da experiência de mundo e de nós mesmos no qual passividade e atividade não são mais alternativa. Mais precisamente, para a recepção de algo é preciso uma passividade ativa que é abertura para a transcendência, e essa abertura, sendo constitutiva da passividade, anula a tradicional contraposição entre atividade e passividade. Isso, no entanto, é o final desse jogo de cartas, até o momento atual de sua obra, que conta, inclusive, com uma segunda etapa, anunciada, aliás, desde o início da primeira (Barbaras, 1999), que conduz a fenomenologia a uma cosmologia e uma metafísica, conforme às exigências do movimento interno da própria fenomenologia, segundo Barbaras (2012, p. 12).

Posto isso, nosso objetivo, aqui, é fazer uma apresentação da filosofia da vida de Renaud Barbaras a partir de sua última obra (até o momento da escrita deste artigo), Le désir et le monde (2016a), que reúne e "completa" a trajetória de seu pensamento em torno do conceito de desejo. Mais precisamente, uma apresentação de sua filosofia da vida em seu sentido mais fenomenológico do que cosmológico e metafísico, dados os limites de nosso artigo. Por fim, avançaremos algumas questões, particularmente sobre a relação com o outro em sua filosofia. 


\section{A noção de desejo}

Encontramos na Introdução de Le désir et le monde (2016a) a perspectiva de uma abordagem que nos parece absolutamente inédita na obra de Barbaras. Trata-se da tentativa de uma exploração do significado da palavra "desejo" na linguagem comum de nossa cultura. ${ }^{5}$ Vamos fazer uma breve passagem por essa Introdução, que, para nós, situa e justifica a importância da pesquisa sobre a questão do desejo, e, dessa forma, o intento da obra inteira de Renaud Barbaras.

Barbaras inicia apontando para uma diferença significativa entre uma extensão muito grande do uso do verbo "desejar", se comparada ao uso mais restrito do substantivo "desejo", geralmente usado para designar o desejo sexual, comumente associado ao amor. Barbaras explorará a ambiguidade do "desejo" tanto em seu uso verbal quanto em seu uso nominal. Em seu uso verbal, o "desejo" encontra-se associado a tudo o que nos move internamente em direção a algo, o que se aplica a um campo amplo de situações diversas, como às nossas necessidades, expectativas, esperanças, aspirações, vontades etc. Nesses casos, o "desejo" aparece como desejo ou necessidade de..., desejo ou expectativa de..., desejo ou esperança que..., desejo ou aspiração a... etc. Nesses casos, o "desejo" aparece e ao mesmo tempo se "ausenta", na medida em que pode ser substituído por tais termos: aspiração a, expectativa de, esperança que, vontade de, necessidade de etc., o que parece apontar para um uso abusivo do termo, visto que substituível por um termo de significado mais preciso (o termo precisão é nosso) (Barbaras, 2016a, p. 7). Mas veremos como essa imprecisão ganhará relevo, justamente para mostrar algo essencial ao próprio desejo.

Em seu uso nominal (substantivo), isto é, como desejo sexual e amoroso, o que inicialmente parece mais simples, porque com um significado mais preciso ou restrito no uso, logo também se mostra ambíguo e complicado, pois, além de o sexual não ser tão fácil de delimitar, também não se sabe ao certo se o desejo não vai além da dimensão sexual, em particular, no amor. Nesse caso, a indeterminação não é propriamente sobre o uso do termo (desejo amoroso), mas sobre a sua essência, cuja ambiguidade aparece na relação entre desejo e amor. Certamente, diz Barbaras, o amor é desejo, mas isso não impede "que ele se especifique e pareça se manifestar, ou melhor, realizar-se

5 Com a ressalva, ao final do livro, de que esse não é propriamente seu objeto de estudo, pois não se trata de esclarecer todas as modalidades semânticas e históricas presentes na complexa questão da relação entre desejo e amor (Barbaras, 2016a, p. 219). 
de maneira privilegiada sobre o plano propriamente sexual" (2016a, p. 8). ${ }^{6}$ Como se o amor e a sexualidade se mostrassem, respectivamente, como o desejo e sua realização, mas essa ambiguidade talvez faça parte ou revele algo de sua própria essência (2016a, p. 8), conforme também adiantamos no uso verbal do termo.

Ora, prossegue Barbaras, "se o uso verbal do termo peca manifestamente por excesso, esse uso intransitivo parece, por sua vez, pecar por falta" (2016a, p. 8), porque assim também designamos uma série de situações diferentes do amor sexual. "É o caso disso que nos impele a reler tal poema, rever tal quadro, ouvir novamente tal trecho de música, e mesmo, simplesmente, sentir novamente tal cor ou tal odor" (2016a, pp. 8-9).

Segundo Barbaras, é o que Paul Valèry chama de "ordem dos efeitos com tendência infinita" (2016a, p. 9), à qual ele reenvia as "sensações inúteis" da arte, que (Barbaras cita Valèry)

"às vezes se impõem a nós e nos excitam a desejar que elas se prolonguem ou se renovem", e que "também tendem, às vezes, a nos fazer querer outras sensações da mesma ordem, que satisfaçam certo tipo de necessidade que elas criaram. A visão, o tato, o odor, a audição, o movimento, nos induzem, pois, a nos demorar no sentir, a agir para aumentar suas impressões em intensidade ou duração" (2016a, p. 9).

E é importante, aqui, prossegue Barbaras, observar que o mesmo impulso ou a mesma tendência presente nas "sensações inúteis" encontra-se também nas atividades teóricas, movidas pela curiosidade e exaltação, como também fazendo parte, pois, da "ordem dos efeitos com tendência infinita" (Barbaras, 2016a, p. 9). E assim o desejo, além de amoroso e sexual, passa a ser também artístico e intelectual.

Em contrapartida, esse extravasamento interno do termo (desejo sexual ou erótico) também ocorre sob a perspectiva de sua importância ou profundidade (2016a, p. 11), pois, como mostra a tradição, nós não dominamos o desejo (2016a, p. 12), e por isso, geralmente, ele aparece como contrário à razão; além disso, aparece como um afeto preciso e privilegiado (2016a, p. 12), pois nele nos sentimos em jogo. Mais precisamente, o desejo aparece como profundamente meu ou como eu mesmo, e ao mesmo tempo, no entanto, como anônimo (2016a, p. 16) e despossessão em direção ao outro (2016a, p. 17). Nesse sentido Barbaras conclui que é difícil dizer tanto quem deseja quanto o que se deseja (2016a, p. 18). 
E é assim que Barbaras passa a uma discussão mais teórica sobre a questão, introduzindo o conceito de pulsão da psicanálise, cuja discussão, ao lado do conceito de recalque $(2008$, p. 244; 2011b, p. 173), ele usará para compor sua filosofia do desejo e da vida e, por fim, sua cosmologia e metafísica. Para Barbaras, o conceito de pulsão expressa uma verdadeira redução fenomenológica do desejo, quando afirma a plasticidade de uma força vital originária da experiência humana, que ao mesmo tempo se mostra como inelutável e independente de um objeto específico para a sua realização. Nesse sentido Barbaras reencontra o que Merleau-Ponty diz na Fenomenologia da Percepção (1945/1994) sobre a primazia e o caráter indeterminado da sexualidade na experiência humana: não sabemos se é a existência que é sexual ou se é a sexualidade que é existencial (Barbaras, 2016a, p. 25).

O que o leva à questão da sublimação ou da natureza da pulsão. Ou seja, trata-se de saber qual é o modo de relação que a pulsão estabelece com o objeto, e não apenas afirmar a variação de objeto ou a plasticidade da pulsão, ou, mais precisamente, entra em jogo a questão do estatuto da percepção e do próprio conhecimento.

A conclusão que Barbaras adianta na Introdução é que, para ser conhecimento, a pulsão não pode ser cega como Freud a entende, isto é, visando apenas à sua descarga e à satisfação que a acompanha. É preciso que ela seja fenomenalizante (2016a, p. 30), isto é, tenha um componente intencional (2016a, p. 31), de modo que o desejo não seja estranho ao conhecimento.

Em contrapartida, se a pulsão não pode ser apreendida como impulso cego, também não devemos, como Husserl, vê-la apenas como um passo em direção à visão racional (2016a, p. 31):

É o desejo mesmo que se sublima, o que significa que ele permanece desejo nesse ultrapassamento mesmo, que ele é ainda desejo mesmo quando ele se faz conhecimento. Longe que o desejo se anule no conhecimento, é antes o conhecimento que, a favor da hipótese da sublimação, revela-se ser, em seu fundo, desejo (2016a, p. 32).

Ou, lembrando mais uma vez Merleau-Ponty na Fenomenologia da Percepção (1945/1994), ao ampliar o sentido da sexualidade humana para a existência de forma geral, não se trata de deserotizá-la.

Barbaras aproveita, então, a questão da sublimação para fazer a distinção entre pulsão e desejo, que ele afinará ao final da obra. A pulsão é força, visa apenas à satisfação, enquanto o desejo é intencional (2016a, p. 32), sua força revela uma relação de sentido. O fato, diz Barbaras (2016a, p. 35), é que o ideal de Freud "de construir uma ideia do homem como homo natura", como mostra Binswanger, acaba reduzindo o desejo ao funcionamento da própria 
pulsão, o "qualitativo ao quantitativo", de modo que se o conceito de pulsão em Freud revela algo de essencial ao próprio desejo (sua plasticidade), tal ganho se perde com o ideal freudiano de uma ciência naturalista. ${ }^{7}$

Em síntese, "Tudo se passa, pois, como se a verdade da sexualidade residisse fora dela, em razão de seu inelutável transbordamento, e a verdade de tudo o que excede a sexualidade residisse na sexualidade mesma" (2016a, p. 34). De onde Barbaras conclui que o desejo une o que a tradição separa: o conhecimento e a afetividade, a força e a visão, o fazer e o ver, o agir e o conhecer. Mas do quê, exatamente, o desejo sexual é desejo? (2016a, p. 34). É o que Barbaras se propõe a discutir nesse trabalho.

\section{O desejo de mundo}

Uma vez exposta a relevância da questão do desejo na Introdução, o primeiro passo será justamente fazer uma fenomenologia do desejo (Parte I do livro), que se dividirá em: "o desejo como tal", "o desejado" e "o desejante". Encontramos, aqui, uma síntese ou o resultado de todo o percurso de Barbaras a respeito daquilo que poderíamos chamar de formação primeira de sua própria filosofia, que se fez, justamente, em torno do conceito de desejo.

Em primeiro lugar, reconhece-se que o desejo parece sempre insatisfeito, isto é, não se esgota na experiência do gozo na sua relação com o objeto, indicando, pois, que o desejo parece carregar uma intenção maior do que aquela que cabe no objeto visado. Como se, portanto, não fosse propriamente o objeto aquilo que é visado pelo desejo, em que pese ele se dirigir sempre a um objeto ou algo específico para a sua realização. $\mathrm{Na}$ verdade, precisa Barbaras, o desejo não é desejo de objeto, mas de relação com o outro (2016a, p. 54).

Em outros termos, o gozo revela a frustração do investimento que fazíamos na relação com o outro, e nesse ponto, diferenciando-se de Lacan, Barbaras (2016a, p. 53) destaca que o gozo, na sua diferença com a experiência de prazer com o objeto, não significa a experiência impossível de fusão com o real da coisa - o que levaria o sujeito à morte (Lacan) -, mas justamente aquilo que acalma a escalada do desejo que pode se perder, confundindo-se com o prazer ou tomando-se por ele. Ou seja, o gozo protege o sujeito do risco do excesso do desejo ou do prazer que a ele se associa e pode, equivocadamente,

7 Mas veremos como, ao final, Barbaras aproveitará o significado de pulsão em uma dimensão ontológica mais ampla, mais precisamente, cosmológica, a par com o significado de desejo. 
ser buscado como seu substituto, como se o prazer fosse aquilo que pudesse preenchê-lo, o que pode colocar em risco a vida do sujeito. ${ }^{8}$

Dito de outra forma, o prazer não é o alvo do desejo, embora acompanhe sua realização e possa assim retornar sobre o desejo e intensificá-lo. É o outro ou, melhor dizendo, a relação com o outro que se mostra como o alvo do desejo.

Ora, em uma passagem que consideramos crucial, Barbaras, desdobrando o sentido fenomenológico da relação com o outro, descobre que o desejo que sentimos pelo outro é, no fundo, desejo pelo mundo que ele representa ou mostra para mim, e é assim que ele (2016a, pp. 90, 205) inverte a direção do desejo erótico ou sexual em Freud. A saber, para Freud a sublimação referese justamente ao desvio necessário do desejo erótico ou sexual para outros objetos e outras relações ou atividades com as quais se faz uma civilização ou um mundo (humano). Mas, agora, descobrimos, segundo Barbaras, que o mundo é a meta primária do desejo, à qual se substitui empiricamente o desejo sexual pelo outro. Ou seja, isso que aparece primeiro para a consciência, a saber, seu desejo do outro ou, mais precisamente, desejo de relação com o outro, revela-se agora como desejo ou atração do mundo que esse outro revela.

Por isso Barbaras critica a psicanálise cujo ponto de partida é a intersubjetividade, oriunda do desejo do outro ou da dependência biológicoafetiva que temos do outro (2016a, p. 125). Uma tese que, como veremos em nossas considerações finais, é plena de consequências.

Mas desejo é desejo de mundo (Barbaras, 2008, p. 286; 2016a, p. 126), e essa é a razão da experiência de frustração no gozo, porque o mundo, como mostra Barbaras, destacando vários fenomenólogos pós-husserlianos por todo o percurso de sua obra (aqui, particularmente Merleau-Ponty), não é passível de intuição objetal, o que fundamenta a inelutável frustração da vida humana e mesmo animal.

\section{A fenomenalização do mundo}

Chegado a esse ponto, fica claro que o desejo não se confunde com a necessidade, cuja satisfação põe fim a ela ou fecha seu ciclo, ainda que a vida necessite de coisas para viver (leben). A necessidade é sempre de algo determinado cuja realização a sacia, enquanto a realização do desejo parece sempre acompanhada de uma frustração, de maneira que o desejo não se 
confirma como de algo determinado. Explorando um pouco o paradoxo dos termos, Barbaras diz que o desejo é desejo de nada (determinado). E aqui cabe o resumo da sua crítica a Jonas, como adiantamos, e que nos parece definitiva: a satisfação de uma necessidade é o retorno ao mesmo, à identidade, sendo, pois, da ordem do ter ("no modo da assimilação ou expulsão") e não da ordem do ser ou daquilo que me diz respeito como parte da minha história (Barbaras, 2016a, p. 64).

Tal crítica, já presente em trabalhos anteriores de sua obra, desenvolve a tese dinâmica e não substancial de sujeito, cujo ser é movimento de ser, de individuação e não de um indivíduo que é (substância) para então se movimentar ou entrar em relação com o outro (sujeito e mundo). Ao contrário, o a priori é o dinamismo da relação na qual se formam correlativamente sujeito e mundo. Uma tese muito rica de consequências, da qual, para nós, a mais importante ou fundamental é a de que não há mundo percebido senão para um "sujeito" desejante. Isto é, sem desejo não se constitui a percepção de coisa nem de mundo. É porque o desejo avança para "fora" que o espaço se abre e o mundo de coisas se forma, o que se aplica ao sujeito também, pois o desejo parece me preceder ou vir de mais longe que eu (Barbaras, 2016a, p. 15). O desejo é, pois, o princípio da subjetivação e formação de mundo concomitantemente. Ou ainda, sem desejo não há fenomenalização, mas, como o desejo só é movimento cuja individuação se forma em seu próprio devir fora, sem o fora não haveria sujeito também. Sujeito e mundo sairão, pois, de um fundo comum, como veremos a seguir. Aqui, o importante é frisar que o mundo não está dado, ele se forma com o desejo que o abre. Nas palavras precisas de Barbaras, "O mundo só é dado na medida em que é desejado, ou ainda, só há mundo desejado" (2016a, p. 84), e essa "é a forma mais profunda da correlação fenomenológica" (2016a, p. 84), que está no seio de todos os atos da consciência, inclusive dos atos objetivantes (esses destacados por Husserl) (2016a, p. 87).

Em outros termos, "longe de se reportar a algo já dado, o desejo abre o mundo no seio do qual todo ente aparece" (2016a, p. 115), eis "o verdadeiro nome da intencionalidade originária" (2016a, p. 115). Ponto de partida (Barbaras, 1999, pp. 160-161) e de chegada da fenomenologia de Barbaras, após longo trabalho em torno da noção de intencionalidade (ou da correlação fenomenológica) à luz do desenvolvimento de uma fenomenologia do desejo.

Ora, se o ser vivo é vivo porque se movimenta ou deseja, e não o contrário (deseja porque é vivo), Barbaras avança a tese de que o corpo vivo é uma propriedade do movimento, e não o inverso (2016a, p. 111), e pergunta: se a individuação vital é o movimento originário de todo ser vivo (individuado), 
ela não reenviaria a um movimento mais profundo que todo movimento que a vida recolhe e prolonga à sua maneira? (2016a, p. 112). Ou seja, se o ser vivo começa pelo movimento, pode ele dar início ao movimento? É preciso reconhecer, e esse é o passo que Barbaras dá para além da fenomenologia, que há um movimento que me precede e me ultrapassa (2016a, p. 112). O que o leva a pensar, pois, para além da fenomenologia, em uma ontologia do desejo.

\section{Cosmologia e metafísica}

Levado, pois, pelas consequências da própria argumentação ou revelação fenomenológica, Barbaras dá o passo em direção ao fundo obscuro (porque anterior à sua fenomenalização) de onde surgem sujeitos e mundos ou a vida individuada com sua percepção de mundo. A saber, se o desejo de todo ser vivo é movimento em direção ao mundo por meio das coisas e dos outros, Barbaras considera necessário aceitar que tal movimento não poderia se autogerar ou criar por si seu próprio ser (movimento). E é por isso que o fundo de onde surgem sujeitos individuados (vivos) e o mundo de coisas determinadas (ou individuadas sem vida) há de ser um fundo de Potência, que Barbaras chamará de Archi-vie (Arquivida). Por razões de limite e para os propósitos de nosso artigo, basta entendermos, aqui, que a vida que usufruímos, ao lado de todos os seres vivos do mundo, é antecedida e provém de uma Vida (arquivida) que é potência de manifestação do mundo ou a vida do mundo propriamente dita, da qual participamos como seres individuados em regime de separação ao lado dos entes sem vida do mundo. Ou seja, é como se todos os entes do mundo (vivos ou não) fossem sedimentos saídos e caídos dessa grande potência de produção e manifestação da Vida, que Barbaras também chama de Arquimovimento.

Do conjunto dos entes reunidos sob a potência da arquivida trata a cosmologia de Barbaras; da separação dos seres vivos da arquivida, que Barbaras intitula arquiacontecimento, ocupa-se sua metafísica. E o importante é marcar, particularmente no caso dos seres vivos, que sua separação da arquivida na condição de seres individuados ou, mais precisamente, em processo de individuação é uma perda de potência que cresce à medida da distância dessa separação. Nesse sentido, os animais estão mais próximos da espontaneidade da potência da arquivida que os homens, que têm o mundo diante de si. Em regime cosmológico, reconhece-se, assim, que a fenomenalização do mundo é anterior à percepção ou ao desejo humano. Como diz Barbaras, nós prosseguimos com o desejo a fenomenalização do mundo que nos antecede. Mas, enquanto os animais vivem de dentro tal manifestação 
(os animais vivem no Aberto), nós o temos diante dos olhos (Barbaras, 2008, 2011b, 2016a, pp. 213-214).

Em termos psicanalíticos - e aqui aparece a reinterpretação da noção de pulsão à qual nos referimos -, a pulsão é a presença da Vida como força ou movimento em nós, enquanto o desejo é aspiração ao mundo. O desejo é sempre desejo de mundo (sentido) impulsionado pela pulsão da vida.

Em síntese, o desejo é metafísico e cosmológico antes de ser antropológico ou desejo do outro, e aqui entra em cena o conceito de Sentimento, casado ou em jogo com o conceito de desejo.

Vale frisar, como dissemos no início, que na esteira de fenomenólogos pós-husserlianos Barbaras assume como a principal tarefa da fenomenologia elucidar a dupla característica da consciência na sua correlação com o mundo, ou seja, o fato de ser a condição de sentido da percepção do mundo e o de estar inserido nele. Ora, até Dynamique de la manifestation (2013) esse era o papel do conceito de desejo na filosofia da vida de Barbaras: "O desejo nasce, portanto, ou antes, consiste na conjunção de uma comunidade ontológica e de uma separação" (p. 270). Ou ainda, "Compreendido até o fim, o desejo representa, pois, um cenário que poderíamos qualificar à primeira vista de ontológico, no qual se unem a comunidade de ser e o ser do arquiacontecimento da cisão" (p. 270). Por isso Barbaras o chamava antes de o "Afeto fundamental" (2011a, p. 125; também 2008, p. 204). Mas, desde Métaphysique du sentiment (2016b), Barbaras trata de destrinchar mais o sentido ontológico do desejo para the conferir o que talvez pudéssemos chamar de seu duplo, que se chamará Sentimento, com letra maiúscula, isto é, o afeto fundamental que será como que o avesso do desejo, visto que não há sentimento, nem com maiúscula nem com minúscula (todos os sentimentos derivados desse Sentimento originário, como veremos a seguir) sem atividade do desejo que nasce com ele.

Mais precisamente, o Sentimento será a uma só vez o testemunho da presença e da ausência da Vida originária em nós, e por isso todo sentimento é sempre nostálgico (2016a, p. 177). Ou seja, o Sentimento é a nostalgia do Ser perdido, que significa a presença que a individuação da vida traz dele em seu seio. Nesse sentido o Sentimento (e todos os sentimentos) é também descrito por Barbaras (2016b, p. 172) como um Contra-acontecimento, isto é, contra a cisão da individuação da vida no seio da arquivida, na medida em que ele é o rastro da Vida (Archie-vie/Arquivida) na abertura perceptiva do ser vivo ao mundo. Por isso o sentimento é o guia do desejo que dele parte como atividade que avança sobre o mundo.

Nesse sentido o Sentimento será o termo final da regressão de uma filosofia da vida enquanto filosofia do sujeito desejante, pois será o sinal 
ou a experiência (prova) fundamental da cisão e do pertencimento da vida individuada de onde parte o desejo e sobre o qual ele se orienta.

Em outros termos, o Sentimento é o pathos originário da individuação da vida e fenomenalização do mundo. Para descrevê-lo, Barbaras utiliza-se de uma expressão parecida com aquela usada por Deleuze-Guattari (1992) para a descrição do campo transcendental em Sartre, com a qual, segundo eles, Sartre recupera os direitos da imanência: "Um fora mais longínquo que todo mundo exterior, porque ele é um dentro mais profundo que todo mundo interior: é a imanência... o fora não exterior ou o dentro não interior" (pp. 7879). É assim que Barbaras (2016a) também descreve a experiência presente em qualquer sentimento, oriunda do Sentimento (pathos) originário: "Nela o sujeito comunica com isso que lhe é o mais exterior através disso que há de mais íntimo" (pp. 171-172). Ou seja, o nascimento da vida (individuada) é o "Sentir puro" (Sentimento) que funda a uma só vez o acolhimento do Mundo no si e a abertura do si ao Mundo (Barbaras, 2016b, p. 202). Desse ponto de vista, se, por um lado, como dissemos, Sartre pode ser considerado abstrato para a expressão desse campo transcendental de sentido, por outro, cremos que esse é o ponto mais próximo da filosofia de Michel Henry a que chega Barbaras em todo o percurso de sua obra, mantendo, no entanto, sua diferença, pois o Sentimento é o estado de Passividade pura (Archi-passivité) de um si (o mais próximo da imanência do sentimento da vida em Henry), que ao mesmo tempo acolhe a presença inteira do mundo ainda indeterminado (portanto, contra Henry, mas note-se que Barbaras assim afirma um acolhimento puro sem conteúdo). Ou seja, na passividade pura nenhum ente afeta ainda o si, porque ela é a atividade que abre para todo afeto, emoção ou sentir no mundo.

Posto isso, podemos destacar os dois sentimentos privilegiados por Barbaras em sua filosofia da vida, como a realização mais exitosa do desejo humano (de mundo): o sentimento estético e o amor.

Ao lado do amor, o sentimento estético é o sentimento empírico mais próximo ou o reflexo mais próprio do Sentimento originário de um si pleno de mundo. Mas, enquanto o conceito de Sentimento originário só é acessível após a regressão fenomenológica operada por Barbaras ao longo da obra (2016a, p. 181), o sentimento estético, ao lado do amor, é sua versão fenomenológica concreta mais próxima. Afinal, nele, o si se esvazia no acolhimento da plenitude do mundo, mundo que não é mais de coisas (individuadas), mas "atmosfera", como destaca Barbaras (2016a, p. 172).

Ora, o sentimento estético também é obra do desejo, visto que avança sobre a profundidade do mundo, ou a recolhe para si; é o sentimento que toca nos limites da experiência da plenitude ou da realização do desejo. Vale frisar 
que, como o Sentimento não é apenas manifestação da cisão, mas também da presença da Vida em nós (Archi-vie), e por isso Barbaras, como dissemos, o chama também de Contra-acontecimento, ele também é um estado de uma satisfação permanente, na medida em que tem ao menos parcialmente aquilo que o desejo procura realizar além ou completar, que é a identificação com a Vida em regime fenomenal ou de mundanização. Voltaremos a esse ponto em nossas considerações finais.

Quanto ao amor, como lembra Barbaras (2016a, p. 219), essa obra iniciase com ele por meio da questão do desejo erótico, que é a forma mais comum ou acentuada de manifestação do desejo.

Vimos que, para Barbaras, o desejo sexual é, no fundo, desejo de mundo, o que significa, conforme passagem anterior que consideramos crucial, que a importância do outro em nossa vida é medida pela importância do (seu) mundo para nós.

Servindo-se de Proust e do modo como Deleuze o lê, Barbaras (2016a) completa que

o sentimento amoroso nasce primeiro em favor do encontro de um mundo [...] antes de se cristalizar sob a forma de um rosto singular [...] O que leva Deleuze, grande leitor de Proust, a afirmar: 'É sempre com mundos que fazemos amor', declaração que Dufrenne comenta assim: 'o gozo nos remete em comunicação com o fundo; o objeto do desejo, quando ele se realiza, não é mais um objeto parcial nem um objeto imaginário, é um objeto que resume nele toda a realidade e que aí me inscreve' (p. 216).

Ou seja, à sua maneira mais comum, isto é, sexual, o desejo chega com o amor ao clímax do seu encontro com o mundo que é o reflexo ou a imagem da Archi-vie (Vida) em nós.

Mas, se o desejo do outro é desejo do mundo, a questão, pergunta Barbaras, é "compreender como isso é possível, qual deve ser o sentido de ser do outro na medida em que o desejo transcendental pode se realizar ou se cristalizar sobre ele" (2016a, p. 189). E sua resposta é que o outro, à diferença dos entes sem vida no mundo, é aquele que invariavelmente abre o mundo, enquanto as coisas tendem a velá-lo.

Ou seja, embora a percepção de qualquer coisa pressuponha o mundo que a forra, tendemos a ficar com a coisa em detrimento do campo no qual ela é, conforme a crítica da fenomenologia à atitude natural. Nos termos de Barbaras, a percepção das coisas tende a velar ou dissimular "o mundo do qual elas procedem", ou "o mundo se ausenta daquele que o apresenta", como ele lembra com Merleau-Ponty, por meio da noção de "invisibilidade do visível", que é "a ostensão do mundo sobre o modo do velamento" (Barbaras, 2016a, p. 190). 
Em contrapartida, a experiência que faço do outro é a experiência de um movimento gestual, ou, simplesmente, de um gesto. É a experiência de apreensão de um desejo (transcendental) (2016a, p. 192), na medida em que o outro ilumina um mundo ou é expressão de um mundo. É o que assistimos inclusive no comportamento animal, como atividade dirigida a um mundo cuja forma é desenhada por seu próprio comportamento (apreensão de alimento, fuga, campo de visão, relação com o congênere, abrigo, esconderijo etc.). De onde Barbaras conclui que o desejo que tenho do outro é o desejo por seu mundo ou, melhor ainda, o outro me conduz ao mundo que sempre desejei.

\section{Considerações finais}

Consideramos que Barbaras inscreve seu nome entre os grandes autores da fenomenologia. Em primeiro lugar, porque sua leitura instigante e crítica de seus principais nomes é capaz de animar a vida do pensamento fenomenológico, embora não tenha sido esse o foco de nosso trabalho. São muitos os autores revisitados por Barbaras, a começar por MerleauPonty, cuja leitura foi responsável pela renovação de seu pensamento na contemporaneidade (Moutinho, 2012, p. 63). A lista, de fato, é extensa. Além do próprio Merleau-Ponty, assistimos a leituras instigantes de Husserl, Heidegger, Hans Jonas, Goldstein, Sartre, Michel Henry, Erwin Strauss, Jan Patocka, Levinas, Maldiney e Dufrenne. Mais ainda, além da fenomenologia, leituras de Bergson, Ruyer, da psicanálise - da qual se destaca Lacan -, além de ensaios sobre a poesia de Fernando Pessoa, Rilke e Paul Valèry.

Em segundo lugar, porque assim ele o fez de uma maneira original a partir de uma noção de desejo, com a qual Barbaras nos oferece uma nova interpretação da correlação fenomenológica, em particular, da relação entre o empírico e o transcendental (Pinto, 2012, pp. 34 e 36), ou uma fenomenologia da vida que ultrapassa uma noção de desejo estritamente antropológica, que nos lembra a ideia de Merleau-Ponty (1964, pp. 317-318) da necessidade de se fazer uma ontologia da psicanálise de Freud. E ele a fez transbordando a fenomenologia em direção a uma cosmologia, contrabalanceada por uma metafísica que evita, assim, uma concepção positivista da vida, da natureza ou do Ser (Barbaras, 2013, p. 299). O negativo surge no Ser por meio dos seres vivos, cujo ser é desejo de mundo ou, em última instância, de outra Vida (arquivida). Por isso Barbaras (2016b, p. 237) cita Lacan contra Heidegger, para marcar que nossa falta constitutiva não é a revelada pela angústia, que é angústia de ser no mundo, angústia que nos singulariza na abertura do mundo como "nada de ente", mas é a falta da falta, que representa, justamente, 
nosso nascimento como cisão da arquivida. Falta da qual, pois, não temos propriamente a experiência, visto que é o "arquifato" ou "fato" transcendental originário da fenomenalização do mundo, ou seja, é anterior e condição de nosso ser no mundo; "arquifato" que, como diz Barbaras (2013, p. 288), encontra-se, pois, aquém de todo fato, rompendo, assim, com os limites da linguagem factual.

Mas perguntamos se Barbaras não fica em certo sentido refém de sua noção metafísica do desejo, sobretudo quando surge propriamente em sua filosofia a figura do outro. ${ }^{9}$ Afinal, como vimos, nosso desejo do outro se subordina, na verdade, a nosso desejo de mundo e, em última instância, de outra Vida. Tudo se passa, então, entre mim mesmo e a falta que me constitui, mesmo Barbaras (2008, pp. 209, 304; 2011a, p. 125) enfatizando que com o desejo do outro (ou do mundo), ao contrário da necessidade, eu verdadeiramente acesso à alteridade porque procuro (realizar) meu ser na transcendência do outro (de seu mundo), pois isso, em última instância, significa que é de mim mesmo que me ocupo no outro (ou no seu mundo). Nos termos enfáticos de Barbaras (2011a):

Todo desejo é no fundo desejo de si, no sentido em que ele procede de uma lacuna ou falta ontológica: ele tende em direção ao outro porque é nesse outro que reside seu ser próprio [...] ele é busca de si no outro, reconciliação consigo ou realização de si pela mediação do outro. Em outros termos, o desejo reenvia sempre a uma alienação e se ele tende em direção ao outro com tanto ardor é porque é nele que reside seu ser próprio. Tal é a razão mais profunda pela qual o desejo não tem, propriamente falando, objeto: seu objeto não é outro que si mesmo, ou, antes o ser do desejante (p. 148).

Nossa intenção não é negar a importância desse ponto, que, em certo sentido, parece apontar para um narcisismo originário e inultrapassável, mas questionar, nele, o que talvez possamos chamar de seu caráter redutor. $\mathrm{Ou}$ seja, é isso, mas não nos parece só isso.

Vamos iniciar com uma questão mais genérica sobre sua metafísica do desejo, em relação à visibilidade ou manifestação do mundo. No fundo, de um ponto de vista fenomenológico e não metafísico, perguntamos se Barbaras não acaba diminuindo a importância da visibilidade do mundo, ou, em outros termos, o desejo da própria finitude. Vamos destacar isso, iniciando com Bataille, com o qual Barbaras (2016a) abre em epígrafe seu trabalho. Bataille (1957/2017) parte da diferença entre a continuidade do Ser e a descontinuidade do ser que é vivo:

9 Ramos (2012, pp. 172-173) também levanta a questão da relevância do outro na filosofia de Barbaras, em um momento anterior de sua obra. 
Somos seres descontínuos, indivíduos que morrem isoladamente numa aventura ininteligível, mas temos a nostalgia da continuidade perdida [...]. Ao mesmo tempo que temos o desejo angustiado da duração desse perecível, temos a obsessão de uma continuidade primeira, que nos religa de maneira geral ao ser (p. 39).

Note-se, também aqui, que tal nostalgia parece mais de ordem metafísica ou mitológica, no sentido em que Freud também afirma sua teoria das pulsões, pois da pulsão de morte temos apenas manifestações de seus efeitos no mundo, particularmente por meio da destruição. Dito de outra forma, no sentido estrito do termo, não temos propriamente experiência dessa nostalgia porque nunca vivemos esse estado de união, contrário à própria vida, que se constitui justamente diferenciando-se da continuidade do ser. ${ }^{10}$ Mas, para nós, o mais importante é o que Bataille (1957/2017) diz a seguir, pois representa o cerne desse primeiro ponto de nossa questão:

Não esqueço que, no desejo de imortalidade, o que entra em jogo é a preocupação de assegurar a sobrevida na descontinuidade - a sobrevida do ser pessoal - mas deixo de lado a questão (grifo nosso). Insisto no fato de que, a continuidade do ser estando na origem dos seres, a morte não a atinge, a continuidade do ser é independente dela, e mesmo, ao contrário, a morte a manifesta (p. 45).

O ponto da nossa questão, ao contrário, é justamente não deixar de lado essa questão (da sobrevida), mais precisamente, destacar que nos parece que há um sentido fundamental para isso. Barbaras também aborda a questão proposta por Bataille, aproximando da morte o limite da vida em direção à sua plenitude. Como ele sintetiza, citando Dufrenne: "Eros, que é princípio de vida, não visa à morte: ele parece querê-la quando visa uma realização que seria acabada, mas o que ele quer é impossivelmente a morte sem a morte" (2016b, p. 129).

Ou ainda, para Barbaras nosso desejo do mundo é tentativa de fuga da ou na finitude. Se da finitude, será por meio do amor e do sentimento estético, mediante os quais buscamos nos unir ao mundo, quer dizer, à sua atmosfera, e não a entes determinados. Em síntese, fugir do estado de separação da arquivida ou da finitude significa viver ao máximo o sentimento de plenitude do mundo no amor ou na estética. Em contrapartida, fugir na finitude é não querer assumi-la, tentando substituir a ausência do mundo - cuja profundidade avança junto com nosso movimento de aproximação -, pelas coisas, em

10 Essa também é a objeção de Jean Wahl a Bataille, após sua conferência em 1957, intitulada "O erotismo e sua fascinação pela morte", à qual ele procura responder como se essa fosse uma situação limite que, de fato, não ocorre nem pode ocorrer (Bataille, 1957/2017, p. 322). 
particular as manufaturadas por meio do consumo, inclusive do outro, no qual "o amor se vê reduzido a uma certa quantidade de satisfação ou de prazer, que não engaja o sujeito em seu ser, é cada vez mais contratualmente organizado e inscrito por isso mesmo no seio do mercado e de suas leis" (Barbaras, 2016b, pp. 175, 181-182). É o que Barbaras também chama de alienação, que poderíamos chamar de alienação existencial para diferenciá-la da alienação metafísica que nos constitui. ${ }^{11}$ Mas, para Barbaras, assumir a finitude não nos parece a meta essencial do desejo que, no fundo, é desejo do impossível, como vimos ao longo deste trabalho. E nisso reside a diferença que gostaríamos de lhe contrapor como questão.

Também poderíamos dizer que o que nos interessa é destacar justamente aquilo que Barbaras também reconhece com o estado de satisfação permanente na vida, pelo simples fato de se estar vivo, pois, como vimos, se o sentimento pode ser o guia do desejo, é porque ele não representa apenas a falta de Vida em nós, mas também sua presença (nosso pertencimento a ela). Queremos, no entanto, deslocar a ênfase da satisfação com a presença da vida em nós (Barbaras) para a satisfação com a ausência do mundo que se revela com sua manifestação. Modificando um pouco o significado de sua noção de Prazer (Barbaras, 2008, pp. 291-292), afirmaríamos o Prazer pela simples expectativa de repetição da manifestação do mundo, mais precisamente, pelo simples movimento de perceber (Prazer com maiúscula, porque da ordem do Desejo transcendental, no qual ocorrem nossas experiências empíricas de desejo e de prazer). Ou seja, mais do que o desejo de união com o mundo, perguntamos se o que desejamos não é, justamente, manter em vida o seu espetáculo. Claro que, como diz Barbaras (2016b, p. 20), isso implica sua fenomenalização pelo desejo, isto é, nosso movimento em direção ao mundo, que também se realiza com a união entre o ver e o fazer. Mas a ênfase não é sobre a direção para o impossível, mas para a possibilidade da manifestação indeterminada do mundo; em poucas palavras, perguntamos se o que desejamos não é $a$ infinitude da finitude.

O segundo ponto de nossa questão, que, de fato é o que mais nos interessa aqui, é afirmar a prevalência do outro sobre o mundo, contrabalanceando a tese de Barbaras de que, como é o mundo que eu desejo, e como é o outro que tem o privilégio da manifestação do mundo para mim, confundo meu desejo de mundo com o meu desejo do outro (Barbaras, 2008, p. 286). Ou

11 Nos termos de Barbaras, "o que quer que seja, a separação sem a qual não poderia haver desejo significa uma alienação no seio do ser, uma alteridade no seio do mesmo" (2016a, p. 121). 
seja, perguntamos se o que desejamos não é o outro mesmo, que, sem dúvida, por razões ontológicas, vem sempre acompanhado de mundo. Ora, como vimos, Barbaras (2008, p. 286; 2016a, p. 190) justifica a proeminência do outro em minha vida afirmando seu poder de manifestação do mundo para mim, ao contrário de minha percepção que vela o mundo a favor das coisas. A isso poderíamos acrescentar que o que me atrai no outro é a não familiaridade de seu mundo para mim (Barbaras, 2016a, p. 226). Tudo somado, é como se o outro fosse capaz de revelar para mim o mundo que eu não alcanço com meu próprio desejo de fenomenalização. A epígrafe que abre o livro antecipa essa tese: "O ser amado para o amante é a transparência do mundo (Georges Bataille, L'Erotisme)". Justificativa que nos parece não fazer completamente jus à importância do amado para o amante ou do outro para nós.

Em termos fenomenológicos, perguntamos se o que me atrai na outra vida, além do mundo que ela revela com sua intencionalidade, não é, justamente, sua intencionalidade mesma, que é o que a define como uma pessoa ou um sujeito como eu. A favor de Barbaras, é preciso frisar que o que diferencia as pessoas é justamente sua fenomenalização de mundo, e aqui talvez se encontre um princípio interessante para uma fenomenologia do charme (do outro). Mas queremos destacar o poder de fenomenalização que, justamente, faz do outro uma pessoa. Intencionalidade que, desde então, tanto pode ser uma ameaça ao meu próprio ser, mas, sobretudo, companheira de mim mesmo. Mais do que o mundo que me falta, tratar-se-ia, então, da companhia do outro, que desperta, em mim, o próprio mundo. Esse outro é tão importante que sou capaz de sacrificar minha vida por ele, ou de escolher sua vida ao invés da minha, para preservar a sua visibilidade do mundo, como dissemos no primeiro ponto. E perguntamos se essa não seria a verdadeira essência do amor. Dito de outra forma, se fosse possível, o que não significa em absoluto desejável, aceitaríamos viver sós em companhia daquele ou daqueles que amamos, mas não sozinhos no mundo, que se desvitaliza sem o outro, isto é, em certo sentido se torna indiferente para nós. ${ }^{12}$ Nessa realidade limite, não tardaríamos a destacar do mundo substitutos imaginários desse outro que se fez ausente. Ou, como diz Barbaras (2016a, pp. 196-197), ensinando-nos, mais uma vez, desta feita sobre a noção de empatia em Merleau-Ponty, o outro é o protótipo de nossa percepção de mundo; mesmo o mundo e as coisas têm fisionomias e 
um modo de ser para nós. Ou seja, como diz Merleau-Ponty, ${ }^{13}$ somos um para outrem natural, mas gostaríamos de destacar que nos parece que o outrem que desejamos, mais do que o mundo, é mesmo outra pessoa. Naturalmente, esse outro também é inobjetável, por sua própria definição, visto que é um ser intencional.

\section{Referências}

BATAILLE, G. (1957). “O erotismo”. 1ª. ed., 2a . reimpr. Tradução de Fernando Scheibe. Belo Horizonte: Autêntica, 2017.

BARBARAS, R. "Le Désir et la Distance". Paris: Librairie Philosophique J. Vrin, 1999.

BARBARAS, R. "Vie et Intentionalité". Paris: Librairie Philosophique J. Vrin, 2003. BARBARAS, R. "Introduction à une Phénoménologie de la Vie". Paris: Librairie Philosophique J. Vrin, 2008.

BARBARAS, R. "La Vie Lacunaire”. Paris: Librairie Philosophique J. Vrin, 2011a.

BARBARAS, R. "Investigações Fenomenológicas”. Curitiba: UFPR, 2011 b.

BARBARAS, R. "Dinâmica da Manifestação". In: Cadernos Espinosanos N. XXVII, Jul-Dez. São Paulo: Departamento de Filosofia da FFLCH-USP, 2012. pp. 11-29.

BARBARAS, R. "Dynamique de la Manifestation". Paris: Librairie Philosophique J. Vrin, 2013.

BARBARAS, R. "Le Désir et le Monde". Paris: Hermann, 2016a.

BARBARAS, R. "Métaphysique du Sentiment”. Paris: Les Éditions du Cerf, $2016 \mathrm{~b}$.

DELEUZE, G.; Guattari, F. “O que é a Filosofia?”. Tradução de Bento Prado Júnior e Alberto Alonso Muñoz. Rio de Janeiro: Ed. 34, 1992.

HENRY, M. "Incarnation”. Paris: Éditions du Seuil, 2000.

MARION, J-C. "D’un Phénomène Érotique”. In: Alter n. 20, Eros. Dijon: Éditions Alter, 2012. pp. 129-142.

MERLEAU-PONTY, M. (1945). "Fenomenologia da Percepção". Tradução de Carlos Alberto Ribeiro de Moura. São Paulo: Martins Fontes, 1994.

MERLEAU-PONTY, M. “Le Visible et le Invisible”. Paris: Gallimard, 1964. (Collection Tel).

MERLEAU-PONTY, M. “A Natureza”. Tradução de Álvaro Cabral. São Paulo: Martins Fontes, 2000.

MOUTINHO, L. D. "De Merleau-Ponty a Barbaras". In: Cadernos Espinosanos $n$. XXVII, Jul-Dez. São Paulo: Departamento de Filosofia da FFLCH-USP, 2012. pp. 63-70. 
PINTO, D. M. "A Vida entre Desejo e Criação: Renaud Barbaras leitor crítico de Bergson”. In: Cadernos Espinosanos N. XXVII, Jul-Dez. São Paulo: Departamento de Filosofia da FFLCH-USP, 2012. pp. 31-61.

RAMOS, S.S. “A Experiência da Falta e o Mistério do Desejo". In: Cadernos Espinosanos N. XXVII, Jul-Dez. São Paulo: Departamento de Filosofia da FFLCH-USP, 2012. pp. 159-178.

VERÍSSIMO, D. S. “A dimensão pulsional do sensível: Elaborações acerca da percepção em Renaud Barbaras”. Psicologia USP, São Paulo, Vol. 24, Nr. 3, pp. 489-507, 2013. 